\title{
COMPLICATIONS OF CANAL WALL DOWN MASTOIDECTOMY
}

\author{
Thapa N*, Shrivastav R
}

\section{ABSTRACT}

This study reviewed 299 patients who underwent canal wall down mastoidectomy between April 1997 to April 2000 in the Department of Ear, Nose \& Throat (ENT), Tribhuvan University Teaching Hospital, Maharajgunj, Kathmandu. Sixty four patients had complications of chronic suppurative otitis media atticoantral type and five patients did not come for follow up. Out of remaining 230 patients, modified radical mastoidectomy was the commonest type of mastoid surgery which was done in $202(87.83 \%)$ patients. Two hundred twenty four $(\mathbf{9 6 . 3 9 \%})$ patients had a dry cavity. Nine (3.91\%) patients developed wound infection, the commonest postoperative complication seen. Although $6(2.61 \%)$ patients developed facial nerve paresis/paralysis, $5 \mathbf{( 2 . 1 8 \% )}$ patients had total recovery of the facial nerve function and only one patient had persistent facial nerve palsy. Intracranial complications were seen in $3(1.30 \%)$ patients and recurrence of disease in $2(0.87 \%)$ patients. One patient died of septicemia. Proper aseptic precaution during and after surgery and adequate knowledge of surgical landmarks is necessary to reduce complications of surgery.

\section{INTRODUCTION}

Chronic suppurative otitis media (CSOM) is an extremely common otolaryngologic problem in Nepal and accordingly mastoid surgery is also one of the commonest ENT surgical procedures. Three basic type of mastoid surgeries can be used to manage chronic suppurative otitis media with or without cholesteatoma. These are combined approach tympanoplasty, modified radical mastoidectomy and radical mastoidectomy. ${ }^{1}$ Combined approach tympanoplasty is a canal wall up procedure which is performed to remove disease from the middle ear and mastoid by way of (a) the mastoid, (b) a posterior tympanotomy, and (c) the transcanal route followed by reconstruction of the middle ear transformer mechanism. ${ }^{2}$ Radical mastoidectomy is a canal wall down procedure performed to eradicate disease from middle ear and mastoid, in which the mastoid air cell system, aditus, attic and middle ear are converted into a common cavity, exteriorized to the external auditory meatus and all diseased tissues, tympanic membrane, malleus and incus are removed, leaving only the stapes in situ. Modified radical mastoidectomy is also a canal wall down procedure but differs from radical mastoidectomy in that tympanic membrane or remnant and ossicular remnant are retained. ${ }^{2}$ Beside these procedures if disease is limited atticoantrostomy and atticotomy can be done.

Atticoantrostomy is synonymous to modified radical mastoidectomy but it is carried out from anterior to posterior ie. exposing the attic first and then proceeding backwards into the aditus and antrum. In atticotomy all or part of the outer attic wall and adjacent deep posterior meatal wall is removed to expose the attic and if necessary, the aditus in order to remove disease limited to these sites. ${ }^{2}$ In our setting modified radical mastoidectomy is the commonest procedure and this is probably true worldwide as well. Normally we combine some type of tympanoplasty procedure with modified radical mastoidectomy as a one-stage procedure. The aims of these operations is to produce a safe and dry ear cavity and to improve hearing. Although these procedures are done to prevent and control complications of disease, the procedures themselve can cause complications.

* Tribhuvan University Teaching Hospital, Maharajgunj, Kathmandu, Nepal.

Address for correspondence : Dr. Narmaya Thapa

Dept. of ENT

TUTH, Maharajgunj, Kathmandu

Email: naramayat@yahoo.com 
About 100 mastoid surgeries are carried out every year in Tribhuvan University Teaching Hospital, Kathmandu. Until now no study has been carried out regarding intra and postoperative complications. Therefore, this study has been undertaken to find out the result of mastoid surgery, complications associated with this type of surgery and the causes of complications.

\section{PATIENTS AND METHODS}

Two hundred ninety nine patients with atticoantral type of CSOM underwent primary canal down mastoidectomy between April 1997 to April 2000 in Tribhuvan University Teaching Hospital, Kathmandu.

Records of these patients were retrospectively reviewed regarding clinical presentation, otoscopic finding, the type of operation, postoperative complications, number and duration of visits after discharge from hospital and results of surgical procedure - whether a dry and safe ear could be achieved postoperatively. Hearing was assessed by pure tone audiometry and plain x-ray mastoids in towne's and lateral oblique views were taken in each patient prior to surgery. Patients having choleateatoma cavity in mastoid x-rays, sclerotic mastoid air cells in mastoid x-rays but disease extended beyond antrum peroperatively with cochlear reserve (bone conduction not more that $30 \mathrm{~dB}$ ) underwent modified radical mastoidectomy and those with profound hearing loss underwent radical mastoidectomy. Patients having sclerotic mastoid air cells with disease limited to attic, aditus, antrum and posttympanum underwent atticoantrostomy and those having disease limited in attic underwent atticotomy the most limited canal wall down technique.

Postoperative complications were divided into 2 groups - early and late. Those complications seen within the first 7 postoperative days were considered as early complications and those complications seen after this period were considered as late complications. The number of follow up visits ranged from 1 to 12 visits and average number of follow up visits was 6 visits. The follow up period ranged from 1 month to 51 months.

\section{RESULTS}

Of the 299 patients who underwent canal wall down mastoidectomy, 64 patients had preoperative complications and 5 patients did not come for follow up. Of the remaining 230 patients, $202(87.83 \%)$ patients underwent modified radical mastoidectomy, $14(6.09 \%)$ patients underwent radical mastoidectomy, $11(4.78 \%)$ patients underwent atticotomy and $3(1.30 \%)$ patients underwent atticoantrostomy (Table I). All 230 patients had complaints of eardischarge and various degree of hearing loss. Dry ear could be achieved in $224(96.39 \%)$ patients. Of these 224 patients, $14(6.09 \%)$ patients had a dry cavity with small dry central perforation. Discharging ear was found in $5(2.18 \%)$ patients (Table II). Twenty four $(10.42 \%)$ patients had postoperative complications. Among early postoperative complications, wound infection was the commonest which was present in $9(3.91 \%)$ patients followed by facial nerve paralysis which occurred in $6(2.61 \%)$ patients. Of these 6 patients with facial nerve paralysis, $5(2.18 \%)$ patients developed facial nerve paresis and $1(0.43 \%)$ patient developed complete facial nerve palsy. The facial nerve paresis
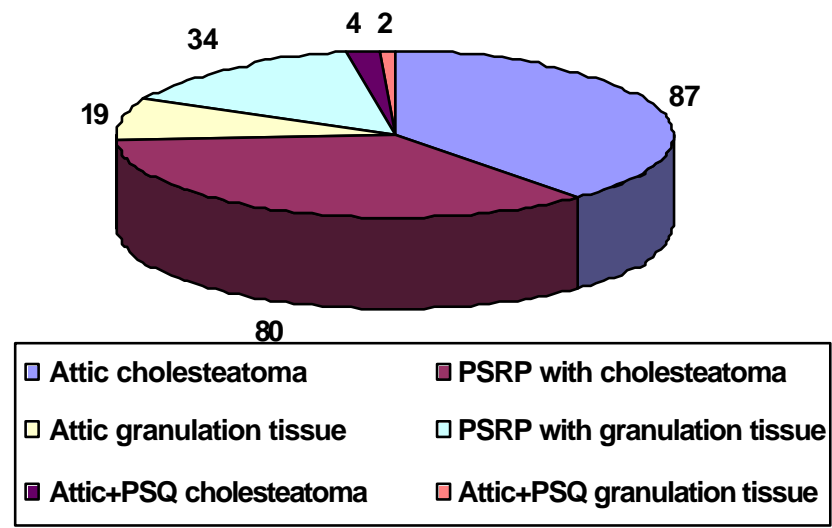

Fig. 1 : Otoscopic Findings

Table I : Types of operation $(n=230)$

\begin{tabular}{lc|c}
\hline \multicolumn{1}{c|}{ Types of Operation } & No. of Patient & \% \\
\hline Modified Radical Mastoidectomy & 202 & 87.83 \\
\hline Radical Mastoidectomy & 14 & 6.02 \\
\hline Atticotomy & 11 & 4.78 \\
\hline Atticoantrostomy & 3 & 1.30 \\
\hline
\end{tabular}

Table II : Results of operation $(n=230)$

\begin{tabular}{lc|c}
\hline \multicolumn{1}{c|}{ Result } & No. of patient & \% \\
\hline Dry cavity & 210 & 91.30 \\
\hline $\begin{array}{l}\text { Dry cavity with small dry } \\
\text { central perforation }\end{array}$ & 14 & 6.09 \\
\hline Discharging ear & 5 & 2.18 \\
\hline Death & 1 & 0.43 \\
\hline
\end{tabular}


Table III : Types of early complications $(n=230)$

\begin{tabular}{|c|c|c|}
\hline Types of complication & No. of patient & $\%$ \\
\hline Wound infection & 9 & 3.91 \\
\hline Facial nerve paresis & 5 & 2.18 \\
\hline Complete facial nerve palsy & 1 & 0.43 \\
\hline Perichondritis & 2 & 0.87 \\
\hline Septicemia (death) & 1 & 0.43 \\
\hline Total & 18 & 7.82 \\
\hline
\end{tabular}

Table IV : Types of late complications $(n=230)$

\begin{tabular}{|c|c|c|}
\hline Types of complication & No. of patient & $\%$ \\
\hline Meningitis & 2 & 0.87 \\
\hline Recurrence of disease & 2 & 0.87 \\
\hline Brain abscess & 1 & 0.43 \\
\hline Partial meatal stenosis & 1 & 0.43 \\
\hline Total & 6 & 2.60 \\
\hline
\end{tabular}

in the 4 patients developed in the $1^{\text {st }}$ postoperative day while in 1 patient it developed in the $5^{\text {th }}$ postoperative day. In all these patients facial paresis recovered totally after removal of pack. Only one patient having facial nerve paralysis did not show any sign of recovery. Two $(0.87 \%)$ patients had perichondritis and 1 patient who developed septicemia died on $6^{\text {th }}$ postoperative day despite of high dose of intravenous antibiotic (Table III). Late complications were seen in 6 patients out of 230 patients. Two $(0.87 \%)$ patients developed meningitis and the same number of patients had recurrence of disease. In addition 1 patient developed brain abscess and 1 patient developed partial meatal stenosis (Table IV).

\section{DISCUSSION}

The main aims of ear surgery in cases of chronic suppurative otitis media (CSOM) is to make the ear dry thereby making the ear safe and also to improve hearing. However, due to various factors complications can occur during and after operation which may vary from simple wound infection to fatal intracranial complications. Complications in mastoid surgery are due to:

Lack of proper aseptic precaution during surgery

Lack of knowledge of important landmarks during surgery.

Destruction of landmarks by disease itself

Improper handling of tissue.

In our study of 230 patients, $210(91.30 \%)$ patients had a dry, self cleansing cavity, and another $14(6.09 \%)$ patients had a dry cavity with small dry central perforation. Out of 5 patients with discharging ear, 1 patient had attic cholesteatoma, 1 patient had attic granulation tissue, and remaining 3 patients had oedematous mucosa of the middle ear. In a study done by Castrillon $\mathrm{R}$ et al., of the 259 patients who underwent canal down mastoidectomy with ossiculoplasty $95 \%$ ears showed a dry, selfcleansing cavity and were disease free. ${ }^{3}$ Another study by Chang $\mathrm{CC}$ et al. reported recurrent otorrhoea in $10(9.6 \%)$ patients thereby achieving dry ear in $90.4 \%$ of his patients. ${ }^{4}$ Our result is comparable to that of others.

The commonest early complication was wound infection which was found in $9(3.91 \%)$ patients. One $(0.43 \%)$ patient who had complete facial nerve paralysis was found to have a dehiscent facial nerve in the mastoid segment due to cholesteatoma. All 5 (2.18\%) patients who had facial nerve paresis were found to have a dehiscent facial nerve canal with intact facial nerve sheath and facial nerve function recovered totally. Garap JP et al. reported postoperative facial nerve paralysis in 3 out of 81 (4\%) patients. ${ }^{5}$ Wormald PJ et al. also reported intraoperative facial nerve paralysis in $17(1.7 \%)$ patients and dead ear in same number of patients. ${ }^{6}$ Harkness $\mathrm{P}$ et al. mentioned facial nerve palsy and dead ear in $10(1.64 \%)$ patients out of 611 patients who underwent mastoidectomy. ${ }^{7}$ In a study done by Nilssen EL et al. out of 1024 consecutive mastoidectomies, a total of $17(1.66 \%)$ facial nerve palsies was identified. Of these, $7(0.68 \%)$ were complete and 10 $(0.98 \%)$ were incomplete. ${ }^{8}$ Facial palsy may develop 1 or 2 days after the operation, particularly when the canal is found dehiscent. ${ }^{9}$ None of our patients developed postoperative profound sensorineural hearing loss though there was vertigo with 1 or 2 episodes of vomiting during the first few postoperative days in a few patients. This may be either due to effect of anesthesia or due to excessive mobilization of stapes.

Regarding intracranial complications, in our study $2(0.75 \%)$ patients developed postoperative meningitis. In both patients dural plate was low lying and was exposed accidentally during surgery. One $(0.38 \%)$ patient developed brain abscess on the $8^{\text {th }}$ postoperative day after discharge from hospital in normal condition. In this patient also the dural plate was exposed during 
surgery. In otoscopic examination all these 3 patients had cholesteatoma in attic. Peroperatively they had disease in attic, aditus, antrum and periantral area, and had undergone modified radical mastoidectomy. One patient developed partial meatal stenosis inspite of having a meatoplasty at the time of surgery.

Most complications can be prevented by paying careful attention to aseptic technique and anatomical landmarks and by exercising good clinical judgement throughout the operative procedure. However, even in the most capable hands, a certain percentage of complications occur. ${ }^{10}$

\section{CONCLUSION}

In our setting modified radical mastoidectomy is the commonest canal down mastoid surgery. Results of these surgical procedures are good with about $95 \%$ safe and dry ear. The commonest complication was wound infection which can be lowered by taking proper aseptic precaution during intra and postoperative period. In order to study long term results regular follow up is necessary.

\section{ACKNOWLEDGEMENT}

Our sincere thanks goes to Royal Nepal Academy of Science and Technology (RONAST), Khumaltar, Lalitpur for financial support. We are grateful to all the faculty members and staffs of ENT department for their kind help and inspiration. We are also grateful to staffs of the record section for their kind help.

\section{REFERENCE}

1 Stephen OH Thonas J M Surgery of Tenporal Bone Air- Cel I System Mastai d and Petrosa. I n: Qd aryngd ogy Head \& Neck surgery. Eds. Cumnings ow $3^{\text {rd }}$ ed. 1998; 3118-3125.

2 Frooko $N$. Reconstruntion of the rindd e er. In Kerr AG Both J B Eds. Scott- Brown's Ool aryngol ogy, vol. 3, 6 6 ed. Butterworth-Hei nemann, 1996: 30.

3 Castrill on R Kos I, Montandon P, Guyct JP. Long termresults of canal wall down nastoi dectony. Schmei z Ned Woncheschr 2000; suppl 125: 585 - 61S.

4 Chang $C$, Chen MK Canal wal I down tympanopl asty with mastoi dectony for advanced chol est eatona. J Qd aryngol $2000 \mathrm{Ct}$; 29 (5): 270-3.

5 Garap J P, Dbey SP. Canal down nastoi dectony: experi ence in 81 cases. Od Nurat. 2001; 22 ( 4): 451-6.

6 Wornal d PJ, N I ssen EL Do the conpl i cati ons of nastoi d surgery d ffer fromthose of the d seese? đi in Qd aryngd 1997; vd. $22(4): 355-7$.

7. Harkness P, Brown P, Fow er S, Gant H Ryan R TophamJ. Mstai dectony aud t; results of the Royal col I ege of Surgeons of Eng and Cin Qd aryngd 1995 Feb; 20 (1): 89-94.

$8 \mathrm{~N}$ I ssen 且, Vernal d H. Faci al nerve pal sy in nestai d surgery. J Laryngol Ad 1997 Feb; 111 (2): $113-6$.

9 G asscock ME, Shanbough GE. The open cavi ty Mastoi d Qperations. In Surgery of the Ear, VB Saunders, Pril add phi a, eds. Mtchel I J, 1990; $4^{\text {th }}$ ed 229-247.

10. Grent DS I throgeric facial pal sy fol loving surgery of chroric suppurati ve oti tis nedia. Indian J arna of Ad ogy 1996; vd 2 (4): 161- 165.

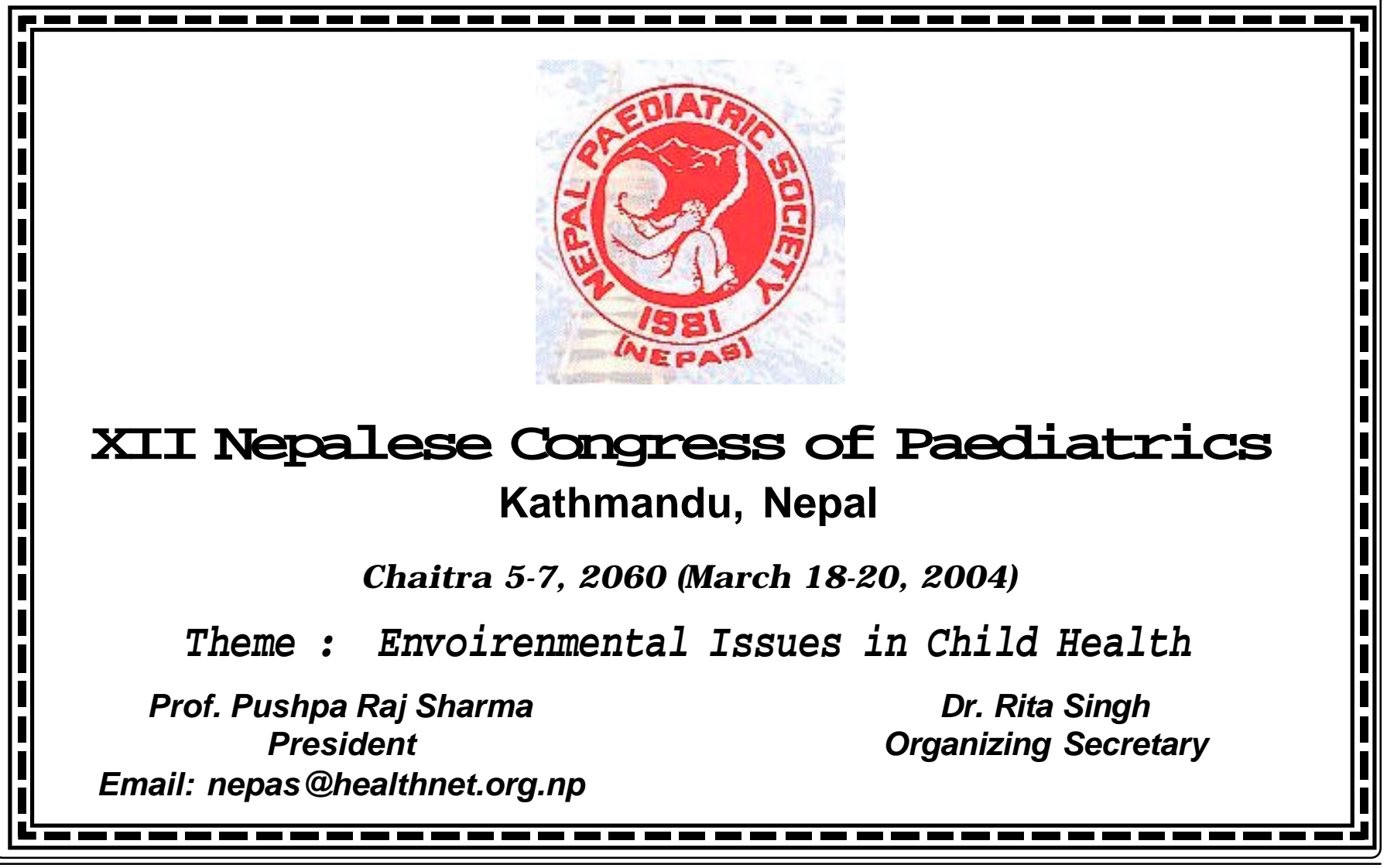

INMA .lanııry - Fehrıary 20ก4 4.3 